\title{
Proteomic analysis of bovine mammary epithelial cells after in vitro incubation with $S$. agalactiae: potential biomarkers
}

\author{
Jinjin Tong ${ }^{1 \dagger}$, Mingwei Sun ${ }^{1 \dagger}$, Hua Zhang ${ }^{1}$, Delian Yang ${ }^{1}$, Yonghong Zhang ${ }^{1}$, Benhai Xiong ${ }^{2 *}$ and Linshu Jiang ${ }^{1 *}$
}

\begin{abstract}
Streptococcus agalactiae is one of the causative agents of subclinical mastitis, a common disease of dairy cows that causes great economic losses in the industry worldwide. It is thought that pathology is mainly due to inflammatory damage of bovine mammary epithelial cells (bMECs); however, the mechanism by which S. agalactiae damages the bMECs is not clear. The aim of this study was to evaluate the inflammatory effects of S. agalactiae on bMECs and the resulting changes in protein profiles. The bMECs were incubated with S. agalactiae for different times and assayed for cell viability by MTT assay, apoptosis by annexin $V$ and propidium iodide dual staining, and morphological and ultrastructural changes by scanning and transmission electron microscopy. Quantitative real-time PCR was used to determine the effect of $S$. agalactiae on expression of mRNA of inflammatory factors in bMECs and protein levels were quantitated by liquid chromatography/mass spectrometry. Exposure to $S$. agalactiae significantly decreased the cell viability and triggered apoptosis, as well as up-regulating TNF-a, IL-1 $\beta$ and IL-6 mRNA, and inhibiting IL-8 expression. S. agalactiae also induced morphological and ultrastructural changes. Furthermore, we identified 325 up-regulated and 704 down-regulated proteins in the treated vs control group. All significant differentially expressed proteins (DSEPs) were classified into three major areas by function: biological processes, cellular components and molecular functions. These differentially expressed proteins included enzymes and proteins associated with various metabolic processes and cellular immunity. Pathway enrichment analysis showed that eight down-regulated signaling pathways were significantly enriched. Exposure to even subclinical levels of S. agalactiae can lead to inflammation and bMEC damage. Our data suggest some possible molecular mechanisms for the harmful effects of subclinical mastitis in dairy cows.
\end{abstract}

Keywords: proteomic analysis, bovine mammary epithelial cells, Streptococcus agalactiae, potential biomarkers

\section{Introduction}

Mastitis is the most common disease in dairy cows. It has high incidence and prevalence within dairy herds ranging from 20 to $60 \%$ and causing more than $\$ 350$ billion in losses in the dairy industry worldwide $[1,2]$. Mastitis is an inflammation of the mammary glands in the udders of

\footnotetext{
*Correspondence: xiongbenhai@caas.cn; kjxnb@vip.sina.com

${ }^{\dagger} J$ injin Tong and Mingwei Sun contributed equally to this work

${ }^{1}$ Beijing Key Laboratory for Dairy Cow Nutrition, Beijing University of Agriculture, Beijing 102206, People's Republic of China

${ }^{2}$ State Key Laboratory of Animal Nutrition, Institute of Animal Science, Chinese Academy of Agricultural Sciences, Beijing 100193, People's Republic of China
}

dairy cows that is mainly caused by infection with pathogenic microorganisms such as Streptococcus agalactiae, Escherichia coli and Staphylococcus aureus. Mastitis infections can be either clinical with obvious swelling and discharge, or subclinical with no overt signs. Subclinical mastitis (SCM) is the most economically detrimental of the two types because it is so common, often goes undiagnosed, and can cause an udder quarter with SCM to lose an average of $17.2 \%$ of its milk production [3].

Since inflammation of the mammary tissues is the primary cause of damage, it is necessary to examine the immune response to $S$. agalactiae infection to determine ways to mitigate it. The innate and cellular immune 
reactions related to mastitis are complex and involve the panoply of immune cells, the bMECs of the mammary gland tissue and the endothelial cells. The bMECs comprise $70 \%$ of the total udder cells and act as the dominant sentinel of the parenchyma as it mounts the first cytokine alert to bacterial invasion [4]. Once the pathogens penetrate the physical barrier of the teat canal, the host innate immune system detects the bacteria through patternrecognition receptors (PRRs), particularly via the toll-like receptors (TLRs) [5]. Binding of microbial components to TLRs activates TLR signaling pathways that trigger several intracellular signal transduction cascades resulting in the production of pro-inflammatory chemokines such as interleukin-8 (IL-8), and cytokines like tumor necrosis factor-alpha (TNF- $\alpha$ ), IL- 6 , and IL- $1 \beta$ leading to inflammation and eventually elimination of the pathogens by leukocytes [6].

The aim of this study was to identify the infective interactions of $S$. agalactiae with bMECs in vitro on the transcriptional and translational level by means of real-time polymerase chain reaction (PCR) and quantitative proteomics using tandem mass tag (TMT)-labeled LC-MS/ MS and to use these protein profiles to identify potential biomarkers of the inflammatory effects and change in cell function.

\section{Materials and methods}

\section{Mammalian cell and bacterial culture}

The primary bovine mammary epithelial cells (bMECs) were kindly provided by Northeast Agricultural University and established as a cell line as described by Chen et al. [7].The bMECs were cultured in Dulbecco's modified Eagle's medium/F-12 (DMEM/F-12, Gibco) supplemented with $10 \%$ heat-inactivated fetal bovine serum (FBS, Gibco), $100 \mathrm{U} / \mathrm{mL}$ penicillin and $100 \mu \mathrm{g} /$ $\mathrm{mL}$ streptomycin at $37{ }^{\circ} \mathrm{C}$ in a humidified atmosphere of $5 \% \mathrm{CO}_{2} / 95 \%$ air. The medium was changed every two days. The S. agalactiae (CVCC 3940) strain used in this study was bought from the China Institute of Veterinary Drug Control and has the capacity to infect bMECs. The S. agalactiae were grown in brain-heart infusion broth (Oxoid, UK) at $37{ }^{\circ} \mathrm{C}$ for $24 \mathrm{~h}$ and the number of CFUs was determined by standard dilution and colony counting on tryptic soy agar plates.

\section{Cell viability assay}

Cytotoxic effects on cell viability were measured by the MTT [3-(4, 5-dimethylthiazol-2-yl)-2, 5-diphenyltetrazolium] assay as previously described (Beyotime, Shanghai, China). The bMECs were inoculated into 96-well plates (3599, Costar) at $1 \times 10^{3}$ cells/well and infected with $S$. agalactiae at a multiplicity of infection (MOI of 50:1 for $1,2,4,6,8$ and $10 \mathrm{~h}$ ) at $37^{\circ} \mathrm{C}$. S. agalactiae suspensions in DMEM/F12 with 4\% FBS and non-infected cells incubated at the same time were used as controls.

The proliferation of bMECs was determined with the MTT cell proliferation and cytotoxicity assay kit (Beyotime, Shanghai, China). After incubation, the supernatants were removed and cells were gently washed three times with phosphate buffer saline (PBS, $\mathrm{pH}$ 7.4) to remove non-adherent bacteria. Then, $10 \mu \mathrm{L}$ of MTT solution $(5 \mathrm{mg} / \mathrm{mL})$ was added to each well and plates were incubated for $4 \mathrm{~h}$ at $37^{\circ} \mathrm{C}$. After incubation, $100 \mu \mathrm{L}$ of formazan solubilizer was added to each well and incubation was continued in the cell culture incubator until all of the formazan was dissolved. The absorbance of the plate was read at $570 \mathrm{~nm}$ in a microplate reader (Thermo Multiscan FC, Shanghai). All experiments were performed in triplicate.

\section{Cell apoptosis assay}

The annexin V-FITC/PI apoptosis detection kit (BioFriend, Beijing, China) was used to detect programmed cell death according to the manufacturer's instructions. S. agalactiae (MOI 50:1) were incubated with bMECs for 2,6 and $12 \mathrm{~h}$ at $37^{\circ} \mathrm{C}$ and cells without S. agalactiae treatment were used as control. The harvested cells were washed twice with cold PBS and resuspended in $250 \mu \mathrm{L}$ binding buffer at a concentration of $1 \times 10^{6}$ cells $/ \mathrm{mL}$. Aliquots of $100 \mu \mathrm{L}$ of cell suspension were transferred into $5 \mathrm{~mL}$ flow tubes and stained with $5 \mu \mathrm{L}$ annexin V-FITC and $5 \mu \mathrm{L}$ propidium iodide. After incubation for $15 \mathrm{~min}$ at room temperature, $400 \mu \mathrm{L}$ of PBS was added to the tubes and cell populations were analyzed within $1 \mathrm{~h}$ by flow cytometry (FACS-ACEA, China).

\section{Cell morphology and ultrastructural analysis}

The bMEC morphology was visualized by scanning electron microscopy (SEM). The cells were grown on cover slips in 6-well dishes $\left(5 \times 10^{5}\right.$ cells/well $)$ and then incubated with S. agalactiae (MOI 50:1) for 2, 4, 6 and $8 \mathrm{~h}$, and uninfected cells were used as control. The bMECs adhered on coverslips were washed three times with cold PBS and fixed with $2.5 \%$ glutaraldehyde at $4{ }^{\circ} \mathrm{C}$ overnight. Fixed cells were dehydrated in a graded series of $30,50,70,80,90$, and $100 \%$ ethanol) for $15 \mathrm{~min}$ at room temperature and ethanol was displaced three times with t-butanol for 10 min each time. After lyophilization and gold coating, cells were viewed on a scanning electron microscope (JEOL JSM-6700F, Japan).

Cellular ultrastructure was analyzed by transmission electron microscopy (TEM). For TEM, cells were cultured in 6-well dishes and incubated with S. agalactiae for $6 \mathrm{~h}$, and the pretreatment of the cells before dehydration was similar to that for SEM. After dehydration by graded ethanol and acetone (three times, $10 \mathrm{~min}$ each), 
cells were embedded in acetone-epoxy resin $(2: 1 ; 1: 2)$ for 3-4 $\mathrm{h}$ and then overnight at room temperature, and finally embedded in pure epoxy resin for $2-3 \mathrm{~h}$ at $37{ }^{\circ} \mathrm{C}$. After the resin polymerized, ultrathin sections were cut with a microtome (Leica EM UC7, Germany), stained with $3 \%$ uranium acetate-lead citrate, and viewed by TEM (Hitachi HT7700, Japan).

\section{RNA extraction and RT-PCR}

The bMECs were incubated with $S$. agalactiae (MOI 50:1) for 1, 2, 4, 6, $8 \mathrm{~h}$ and non-infected cells were used as control. Total RNA was extracted using the Total RNA Kit I (Omega, Guangzhou, China) according to the manufacturer's protocol. The absorbance values at 260 and $280 \mathrm{~nm}$ were read to assess RNA concentration and purity in the samples, and RNA integrity was assessed by electrophoresis on $2 \%$ agarose gels $(\mathrm{m} / \mathrm{v})$. The RNA $(2 \mu \mathrm{g})$ was reverse transcribed into cDNA with the PrimeScriptTM RT reagent Kit (TaKaRa, Japan). Quantitative real-time PCR (qRT-PCR) reactions were performed using SYBR green Premix Ex TaqII (Tli RNaseH Plus) (TaKaRa, Japan) on a Roche LightCycler 96 (Basel, Switzerland) in a total volume of $20 \mu \mathrm{L}$ using 96-well plates. The primers used in this experiment are shown in Table 1 . All target mRNAs were normalized to $\beta$-actin mRNA level. The relative expression of the target genes was quantified using the $2^{-\Delta \Delta \mathrm{Ct}}$ method.

\section{Protein extraction and proteomic analysis}

After $6 \mathrm{~h}$ incubation, cells were harvested by trypsin digestion, and sonicated three times on ice using a highintensity ultrasonic processor (Scientz) in lysis buffer containing $8 \mathrm{M}$ urea, and $1 \%$ protease inhibitor cocktail. The supernatant was collected and the protein concentration was determined with a BCA kit according to the manufacturer's instructions. The protein lysates were reduced with $5 \mathrm{mM}$ dithiothreitol for $30 \mathrm{~min}$ at $56{ }^{\circ} \mathrm{C}$ and alkylated with $11 \mathrm{mM}$ iodoacetamide for $15 \mathrm{~min}$ at room temperature in darkness. The lysates were then diluted by adding $100 \mathrm{mM}$ triethylammonium bicarbonate (TEAB) with a final urea concentration of less than $2 \mathrm{M}$. Finally, trypsin was added at 1:50 trypsin-to-protein mass ratio for the first digestion overnight at $37{ }^{\circ} \mathrm{C}$ and 1:100 trypsin-to-protein mass ratio for a second digestion of $4 \mathrm{~h}$. After trypsin digestion, the samples were desalted on a Strata X C18 SPE column (Phenomenex) and vacuum-dried. The peptide digest was reconstituted in $0.5 \mathrm{M} \mathrm{TEAB}$ and processed according to the manufacturer's protocol for TMT labeling.

\section{HPLC fractionation and LC-MS/MS analysis}

The tryptic peptides were separated into fractions by high-pH reverse-phase HPLC on an Agilent 300ExtendC18 column (5 $\mu \mathrm{m}$ particle size, $4.6 \mathrm{~mm}$ ID, $250 \mathrm{~mm}$ length) using a chromatograph (Thermo EASY-nLC 1000 Nano HPLC, USA) and dissolved in $0.1 \%$ formic acid (solvent A). Samples were directly loaded onto a homemade reversed-phase analytical liquid chromatography column (15-cm length, $75 \mu \mathrm{m}$ i.d.) connected to an EASY-nLC 1000 UPLC system. The gradient consisted of an increase from 6 to $23 \%$ solvent B $(0.1 \%$ formic acid in $98 \%$ acetonitrile) over $26 \mathrm{~min}, 23 \%$ to $35 \%$ in $8 \mathrm{~min}$ and increasing to $80 \%$ in $3 \mathrm{~min}$, then holding at $80 \%$ for the last $3 \mathrm{~min}$, all at a constant flow rate of $400 \mathrm{~nL} / \mathrm{min}$. Then the peptides were subjected to a nanospray ionization source followed by tandem mass spectrometry (MS/MS) on a Q ExactiveTM Plus (Thermo) coupled online to the UPLC.

The applied electrospray voltage was $2.0 \mathrm{kV}$. The $\mathrm{m} / \mathrm{z}$ scan range was 350 to 1800 for full scan, and intact peptides were detected by the OrbitraP at a resolution of 70,000. Peptides were then selected for MS/MS using an NCE setting of 28 and the fragments were detected in the Orbitra $P$ at a resolution of 17,500 . The data-dependent

Table 1 Oligonucleotides used in this study

\begin{tabular}{|c|c|c|c|}
\hline Primer & Sequence, $5^{\prime}-3^{\prime}$ & Size (bp) & Source \\
\hline$\beta$-actin forward primer & TCACCAACTGGGACGACA & 206 & Fu et al. [37] \\
\hline$\beta$-actin reverse primer & GCATACAGGGACAGCACA & & \\
\hline TNF-a forward primer & TCTTCTCAAGCCTCAAGTAACAAGC & 104 & Lahouassa et al. [23] \\
\hline TNF-a reverse primer & CCATGAGGGCATTGGCATAC & & \\
\hline IL-1 $\beta$ forward primer & CTCTCACAGGAAATGAACCGAG & 152 & Lahouassa et al. [23] \\
\hline $\mathrm{IL}-1 \beta$ reverse primer & GCTGCAGGGTGGGCGTATCACC & & \\
\hline IL-6 forward primer & ATGCTTCCAATCTGGGTTC & 269 & Fu et al. [37] \\
\hline IL-6 reverse primer & TGAGGATAATCTTTGCGTTC & & \\
\hline IL-8 forward primer & ACACATTCCACACCTITCCA & 124 & Fu et al. [37] \\
\hline IL-8 reverse primer & GGTTTAGGCAGACCTCGTTT & & \\
\hline
\end{tabular}


procedure alternated between one MS scan followed by $20 \mathrm{MS} / \mathrm{MS}$ scans with a $15.0 \mathrm{~s}$ dynamic exclusion. The automatic gain control (AGC) was set at $5 \mathrm{E} 4$ and the fixed first mass was set at $100 \mathrm{~m} / \mathrm{z}$.

\section{Proteomic data analysis}

The resulting MS/MS data were processed using the Maxquant search engine (v.1.5.2.8). The tandem mass spectra were searched against the UniProt Bos taurus database concatenated with a reverse decoy database. Gene Ontology (GO) software was used to analyze enrichment for signaling pathway proteins and for the putative protein functionality present in and between each sample (http://www.ebi.ac.uk/GOA/). The Kyoto Encyclopedia of Genes and Genomes (KEGG) Pathway Annotation was used to determine the number of pathways detected in each sample and the number of proteins of each pathway represented in each sample (http://www. genome.jp/kegg/).

\section{Statistical analysis}

All experiments were performed independently at least three times and the results are presented as mean \pm standard error of the mean (SEM). Statistical analysis was performed using Student's $t$ test. Statistical significance was defined as $p<0.05$.

\section{Results}

\section{Viability and apoptosis of bMECs after S. agalactiae incubation}

Incubation with $S$. agalactiae caused a significant decrease in the viability of bMECs from $27.1 \%$ loss at $2 \mathrm{~h}$ $(p<0.05)$ to $87.9 \%$ after $12 \mathrm{~h}$ exposure $(p<0.01)$ compared to control cells in the absence of bacteria (Figure 1).

The induction of apoptosis in bMECs was slightly increased after $2 \mathrm{~h}$ with $S$. agalactiae $(p<0.05)$ compared to uninfected controls, but from 6 to $12 \mathrm{~h}$ exposure, the number of apoptotic/necrotic cells in early apoptosis increased to $83.36 \%(p<0.01)$. The apoptosis of BMECs

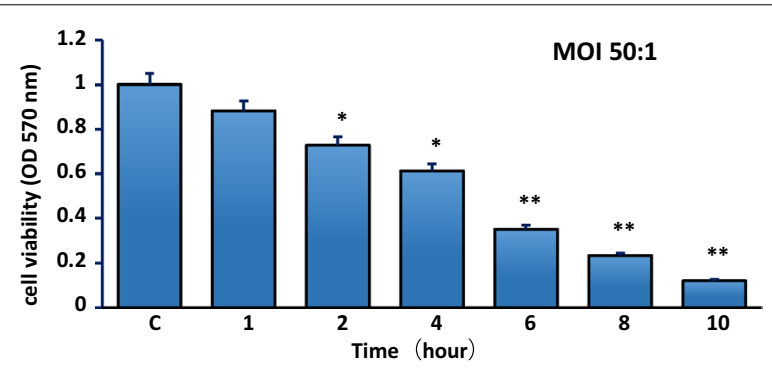

Figure 1 Cytotoxicity of S. agalactiae to bMECs. Cell viability was determined by MTT assay. Values are presented as mean \pm SEM. ${ }^{*} p<0.05,{ }^{* *} p<0.01$ as compared with the control group. induced by $S$. agalactiae, especially early apoptosis, was significantly increased in a time-dependent manner (Figure 2).

\section{Morphological and ultrastructural analysis of bMECs}

Scanning electron microscopy (SEM) was used to explore the interaction between bMECs and S. agalactiae and detect any overt cell changes. Control bMECs without bacterial infection showed no morphological changes at the end of the incubation period (Figure 3A). S. agalactiae appeared as single or multiple chains (Figure 3B). At $2 \mathrm{~h}$ infection, some bMECs showed slight shrinkage (Figure 3C) and S. agalactiae adherence (Figure 3D). After 4 and $6 \mathrm{~h}$ infection, there was obvious cellular shrinkage, dysmorphosis, desquamation and cell adhesion edge deterioration; even some cell disruption (Figure 3E-H). After $4 \mathrm{~h}$ infection, cell microvilli elongated and wrapped S. agalactiae (Figure 3E), but most of cell microvilli disappear after $6 \mathrm{~h}$ infection and $S$. agalactiae adhere to the cell surface (Figure 3G, H). Finally, most cells were breaking up by $8 \mathrm{~h}$ infection. It appears that $S$. agalactiae adhere to the cell surface and secrete toxic substances that cause cell damage.

Transmission electron microscopy (TEM) was used to visualize the ultrastructural changes in bMECs with $S$. agalactiae infection. In the control group, cells have a complete structure with clear cell membrane rich in microvilli, distinct cytoplasmic and nuclear areas and abundant mitochondria (Figures 4A, B). After $6 \mathrm{~h}$ infection with $S$. agalactiae, the ultrastructure was markedly changed, including organelle disorder, loss of microvilli and also expansion of the perinuclear space (Figure 4C). From (Figures 4D-F), we can see swollen endoplasmic reticulum (d), cristae degeneration and accumulation of dense granules in mitochondria (e), chromatin fragmentation and spreading to the nuclear membrane edge (c), and rupturing of the cell membrane (f).

\section{Expression of pro-inflammatory cytokines by bMECs}

The mRNA expression of TNF- $\alpha$, IL- 6 , IL- 8 and IL- $1 \beta$ in bMECs induced by $S$. agalactiae was determined by RT-PCR. Results showed that the expression of IL- $1 \beta$ was significantly upregulated after $2 \mathrm{~h}$ infection $(p<0.01)$ (Figure 5A). IL-6 mRNA expression was markedly upregulated by $S$. agalactiae in a time-dependent manner after $1 \mathrm{~h}$ post-infection $(p<0.01)$ (Figure $5 \mathrm{~B})$. Strikingly, no difference was observed in IL-8 mRNA expression except that it was significantly downregulated at $1 \mathrm{~h}(p<0.05)$ (Figure 5C). Compared with control, the TNF- $\alpha$ expression was significantly downregulated at $1 \mathrm{~h}(p<0.05)$ but was much higher after 6 and $8 \mathrm{~h}$ of $S$. agalactiae infection $(p<0.01)$ (Figure 5D). 

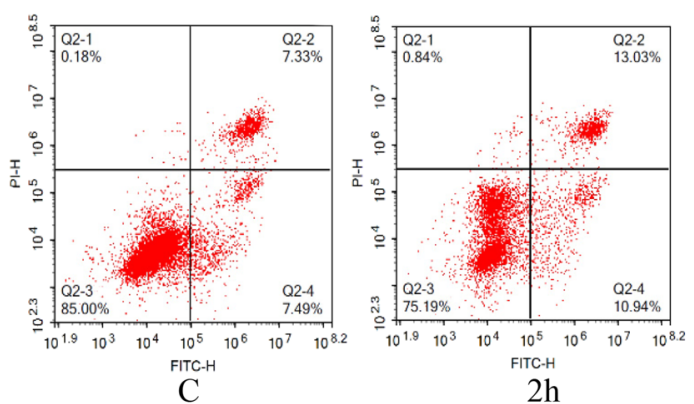

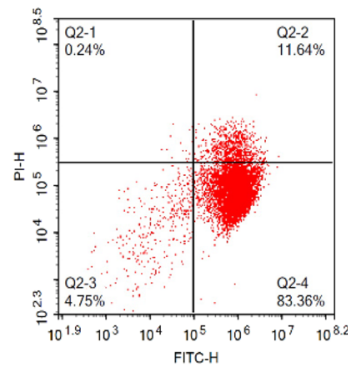

$6 \mathrm{~h}$

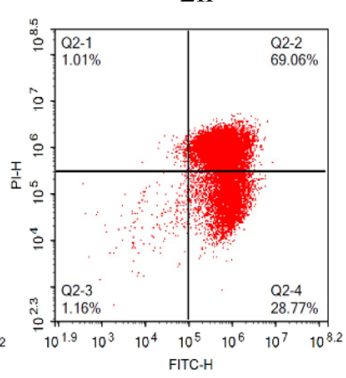

$12 \mathrm{~h}$

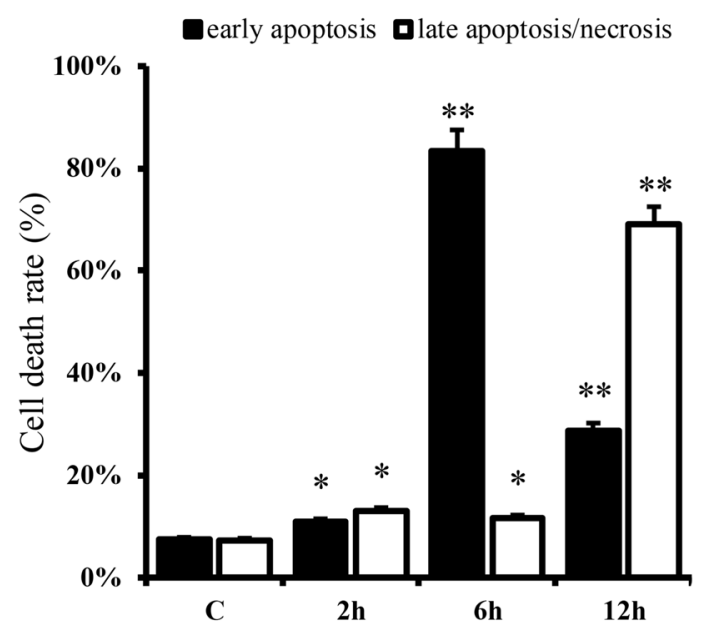

Time

Figure 2 Apoptosis and necrosis of bMECs analyzed by flow cytometry with annexin V/propidium iodide (PI) dual staining. A Two dimensional scatter plots of FITC annexin V vs. PI from flow cytometry. Cells staining negative for FITC annexin V and PI in the lower left quadrant are live cells. Cells staining positive for FITC annexin V and negative for PI in the lower right quadrant represent early apoptosis. Cells staining positive for both FITC annexin V and PI in the upper right quadrant are the late apoptotic/necrotic cells. B Percentage of early apoptotic cells and late apoptotic/necrotic cells. Data are presented as mean \pm SD of three independent experiments. ${ }^{*} p<0.05,{ }^{* *} p<0.01$ as compared with the control group.

Protein identification and quantification using TMT-LC-MS/ MS

Two experimental groups containing six different samples were analyzed using TMT labeling to quantitate protein levels. A total of 5239 proteins was identified, of which 4601 contained quantitative information. A 1.5-fold threshold and t-test $(p<0.05)$ were used to establish valid protein changes. Among the proteins identified from bMECss incubated with $S$. agalactiae and quantified, 325 were up-regulated and 704 were down-regulated.

We performed statistics on the distribution of quantified proteins using GO secondary annotations classification, including three major classes: biological processes (BP), cellular components (CC), and molecular functions [8] (Tables 2 and 3). By using GO enrichment analysis of the functions of the differentially expressed proteins, we found among the up-regulated proteins that the top eight GO terms for MF $(p<0.01)$ included ATPase, active transmembrane transporters, nucleobase-containing compound kinases, nucleoside-triphosphatases, etc. The top three GO terms for CC $(p<0.01)$ were nucleosomes, DNA packaging complexes, and protein-DNA complexes. There were ten GO terms for BP involving nucleosome assembly, phosphatidylinositol biosynthesis, cytochrome complex assembly, organic anion transport, etc. (Figure 6A). Among the down-regulated proteins, the top eight $\mathrm{GO}$ terms for $\mathrm{CC}$ were proteasome core complex, cytoplasmic ribonucleoprotein granules, etc. The top eight GO terms for MF include threonine-type endopeptidase activity, threonine-type peptidase activity, etc.; the top 14 GO terms for BP are regulation of cell shape, chaperone-mediated protein folding independent of cofactor, etc. (Figure 6B).

Pathway enrichment analysis showed that eight downregulated signaling pathways were significantly enriched: proteasome, cell adhesion molecules (CAMs), ribosome, glycolysis/gluconeogenesis, spliceosome, Staphylococcus aureus infection, pentose phosphate pathway and purine metabolism (Figure 7A). In addition, among the down-regulated proteins, 287 participated in 42 specific pathways, including glycometabolism (14\%), amino acid synthesis and metabolism (18\%), ribosomes (9\%), cellular immunity (9\%), spliceosomes $(9 \%)$, purine metabolism (6\%), proteasomes (6\%) and cell adhesion molecules (4\%) (Figure 7B). In addition, among the top ten differentially expressed up- or down-regulated proteins there were several uncharacterized ones (Tables 4 and 5). Some proteins with special functions mentioned in some studies like dimethylarginine dimethylaminohydrolase 1 

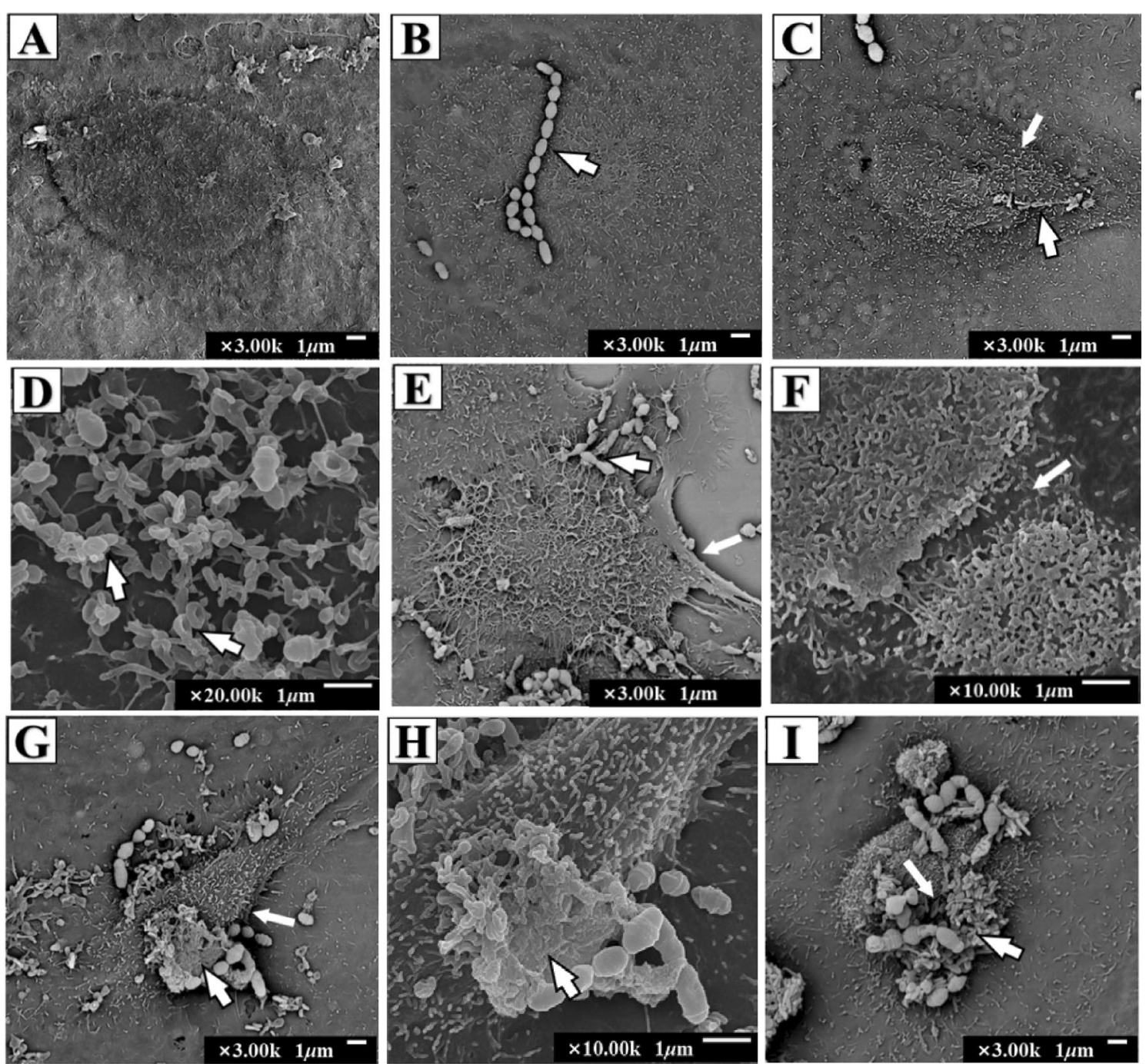

Figure 3 Scanning electron photomicrographs showing interaction of bMECs infected with S. agalactiae. A Untreated bMECs; B S. agalactiae (arrow); C cell shrinkage and slight bulging at $2 \mathrm{~h}$. D Microvilli trapping S. agalactiae at $2 \mathrm{~h}$ (arrows). E A cell with folded edge (thick arrow) and microvilli extending and wrapping S. agalactiae (thin arrow) at $4 \mathrm{~h}$. F Cell fracture at $4 \mathrm{~h}$; $\mathbf{G}$ cells with obvious shrinkage, dysmorphosis, desquamation and microvilli disappearance (thin arrow) at $6 \mathrm{~h} ; \mathbf{H}$ S. agalactiae secrete substances that adhere to the cell surface at $6 \mathrm{~h}$ (arrow); and $\mathbf{I}$ cell membrane breakage at $8 \mathrm{~h}$.

(DDAH1), peroxiredoxin-6 (PRDX6), epithelial cell adhesion molecule (EPCAM), were down-regulated.

\section{Discussion}

In this study, we hypothesized that the interaction of $S$. agalactiae with bMECs caused inflammatory effects and changes in cell function that were reflected in altered expression of proteins, some of which may be used as potential biomarkers for diagnosis of mastitis. This hypothesis was supported by the finding that $S$. agalactiae significantly affected the viability of bMECs in a time-dependent manner. $S$. agalactiae could adhere to the cell surface, where they were entangled with microvilli and eventually led to cell rupture. S. agalactiae is well known as an important pathogen frequently associated with bovine mastitis and a cause of huge economic losses in dairy herds [9]. In particular, S. agalactiae can colonize mammary epithelium and produce virulence factors that affect the physiological function of bMECs and can even result in cell death [10]. Some studies suggested that the pathopoiesis of $S$. agalactiae depended on the production of virulence factors such as capsular polysaccharides and surface proteins like Rib and hyaluronate lyase [11], and that the intracellular damage and induction of apoptosis 

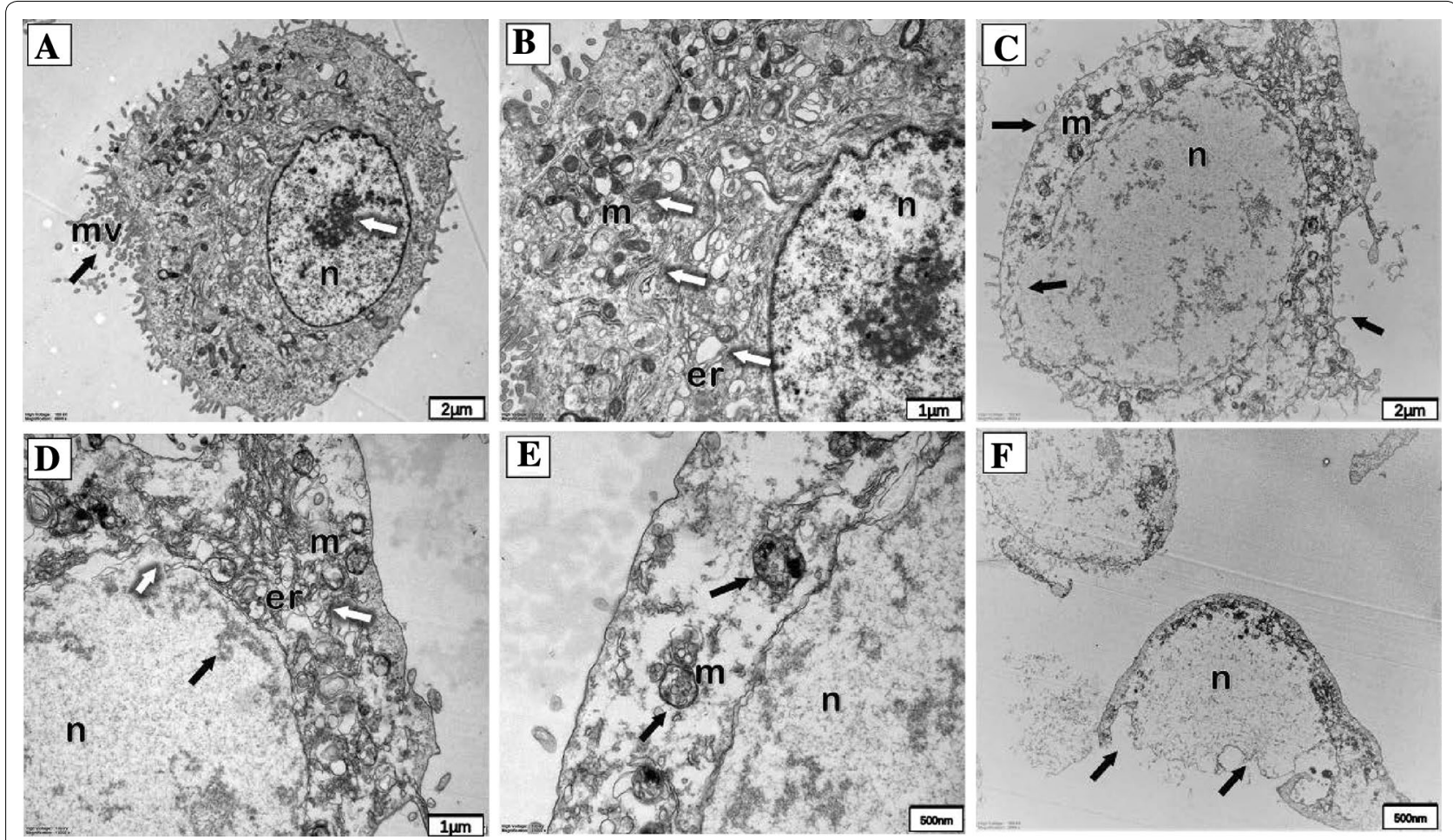

Figure 4 Transmission electron photomicrographs showing pathological ultrastructural changes in bMECs infected with S. agalactiae. A, B Non-infected bMECs are rich in microvilli and have abundant organelles in cytoplasm, especially mitochondria; $\mathbf{C}$ after $6 \mathrm{~h}$ infection, bMECs show deformation, loss of microvilli, nuclear swelling and rupture (black arrows); D Organelle disruption and swollen endoplasmic reticulum (white arrows), chromatin spread to the nuclear membrane edge (black arrow). E Mitochondria with decreased electron density, cristae degeneration and accumulation of dense granules. F Some cells show disruption and loss of organelles. $n$ nucleus, $m$ mitochondrion, $m v$ microvillus, er endoplasmic reticulum.

in bMECs may be attributed to these virulence factors [12]. The results demonstrated that $S$. agalactiae possessed adhesion abilities and cytotoxic effects that could destroy cells in a relatively short time through apoptosis/ necrosis.

The rapid inflammatory response stimulated by $S$. agalactiae has been confirmed in bMECs, and was characterized by release of proinflammatory cytokines, such as IL- $1 \beta$, TNF- $\alpha$ and IL-8. It has been reported that IL- $1 \beta$ and TNF- $\alpha$ play critical roles in the host defense against infection and are responsible for early inflammatory responses [13]. In a mouse model of infectious mastitis, an increase in IL-1 $\beta$ and TNF- $\alpha$ levels was detected in the mammary glands after a 24 -h intramammary challenge with S. agalactiae [14]. In agreement with this finding, we observed in bMECs incubated with S. agalactiae that IL-1 $\beta$ gene expression was significantly increased after $2 \mathrm{~h}$. However, the level of TNF- $\alpha$ mRNA initially decreased after $1 \mathrm{~h}$ exposure to $S$. agalactiae and then increased again at 6 and $8 \mathrm{~h}$. Although IL- 6 is a pleiotropic cytokine that can be either pro- or anti-inflammatory [13], we found that exposure to S. agalactiae stimulated IL-6 mRNA expression in bMECs in a timedependent manner. This was in line with a previous study that $S$. agalactiae stimulated a significantly greater release of IL- $1 \beta$, IL- 6 , and TNF- $\alpha$ in mouse macrophages [15]. IL-8 is a critical chemotactic factor that can recruit neutrophils from the bloodstream to sites of infection [16]. In the present study, S. agalactiae induced a cellular inflammatory response in bMECs that inhibited the expression of IL-8 in the early stages of inflammation. Therefore, we concluded that the inflammation resulting from S. agalactiae infection could injure bMECs and reduce milk production.

In this study, proteomic analysis of bMECs infected by $S$. agalactiae was carried out by obtaining quantitative TMT measurements. Compared with control cells, we detected 325 up-regulated and 704 down-regulated proteins. Proteomic analysis revealed that these differentially expressed proteins included enzymes and proteins associated with various metabolic processes and cellular immunity. Our results also showed that some proteins were involved in metabolism of amino acids, sugars and purines, cell adhesion, cytoskeletal remodeling, protein 

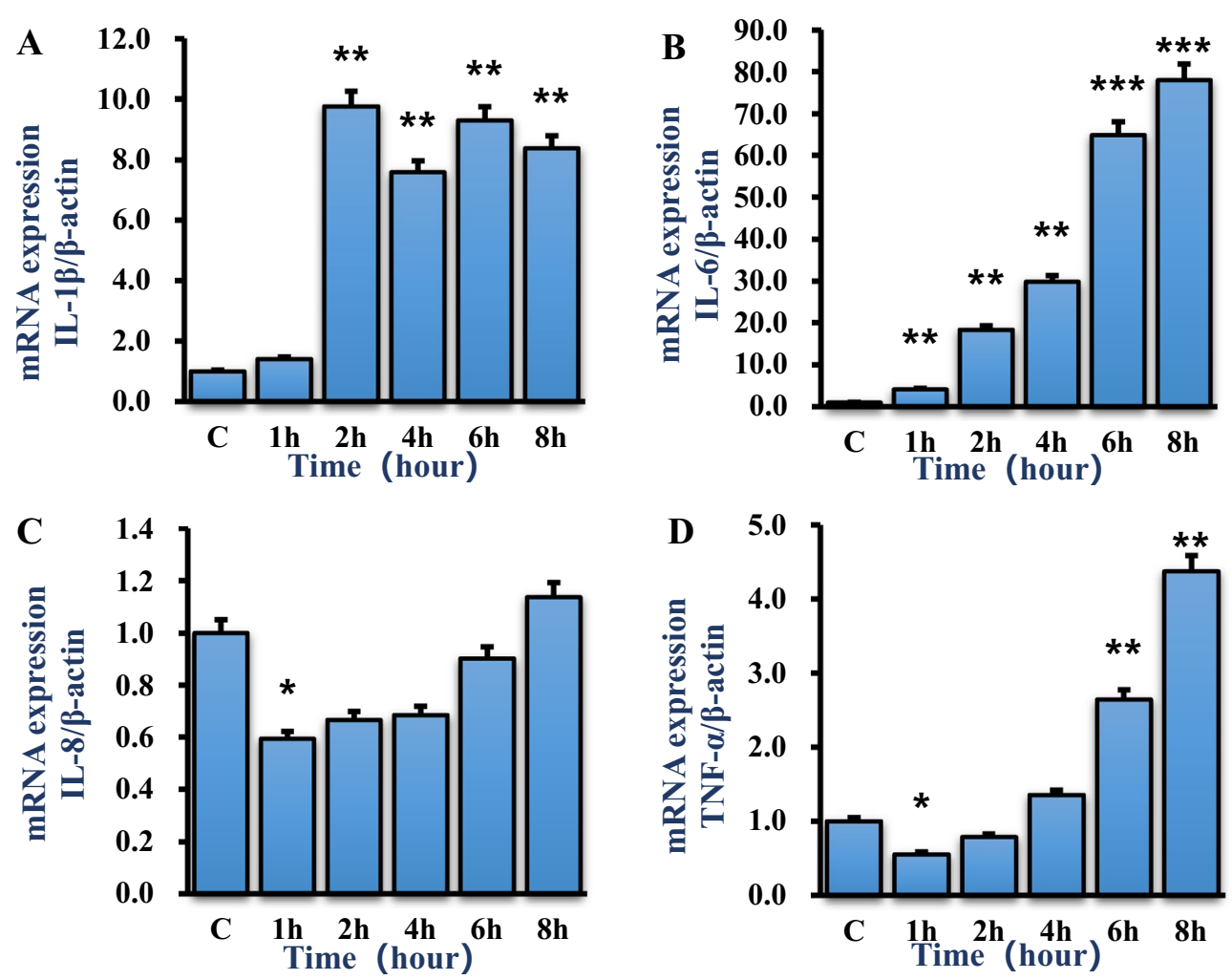

Figure 5 S. agalactiae infection increases mRNA expression of IL-1 $\beta$, IL-6, IL-8, TNF- $\boldsymbol{\alpha}$. A Relative mRNA expression of IL-1 $\beta$. B Relative mRNA expression of IL-6. C Relative mRNA expression of TNF-a. D Relative mRNA expression of IL-8. Results are presented as mean \pm SEM of three independent experiments. ${ }^{*} p<0.05,{ }^{* *} p<0.01,{ }^{* *} p<0.001$ as compared with the control group.

processing and transporter functioning. Previous studies showed that the amount of milk produced by dairy cows was highly dependent on their body's energy supply, and the physiological functioning of the mammary gland was closely related to the rate of carbohydrate metabolism [17]. In the present study, some differentially expressed proteins such as pyruvate kinase M2, fructose1,6-diphosphatase $1 / 2$, fructose diphosphate aldolase, and glyceraldehyde-3-phosphate dehydrogenase, participated in several carbohydrate metabolic pathways: galactose metabolism, glycolysis/glycogenesis, pyruvate metabolism, starch-sucrose metabolism and the pentose phosphate pathway. These proteins are important in the energy supply pathway, which can have a major impact on mammary gland function. Pyruvate kinase, which converts phosphoenolpyruvate to pyruvate is the key enzyme in the last step of glycolysis, and pyruvate kinase M2 is the key regulator of anaerobic glycolysis, which supplies energy for cells [18]. Likewise, fructose-1,6-diphosphatase, which catalyzes the conversion of fructose-1,6-diphosphate into fructose-6-phosphate in the glycolytic pathway [19] and glyceraldehyde-3-phosphate dehydrogenase which promotes ATP synthesis [20], were all significantly down-regulated after infection with $S$. agalactiae in the present study. Thus, the metabolism of bMECs was inhibited and ATP synthesis was reduced. This inhibition would have caused an energy and metabolic insufficiency that could affect cell proliferation, lactoprotein and lactose synthesis and milk production [21].

As a first-line of defense against pathogens invading the mammary gland, bMECs play a critical role in pathogen recognition and the innate immune response [22]. It has been reported that there are many pathogen recognition receptors (PRRs) on the cell membranes of bMECs, which can accurately identify the pathogen-associated molecular patterns (PAMPs) of many pathogens. This signal recognition triggers an immune response that promotes synthesis and release of various inflammatory factors, induces immune cell migration, and ultimately eliminates the pathogenic bacteria [23]. We found that among the down-regulated differential proteins, proteasome activator 1 [24], cathepsin B [25], cathepsin D [26] and cathepsin L2 [27] played important parts in the recognition of bacteria and in antigen presentation. In addition, claudin-3 (CLDN3) and claudin-4 (CLDN4) [28] are major structural molecules of the tight junctions that link 
Table 2 Distribution of up-regulated proteins in GO secondary annotations (T/C)

\begin{tabular}{|c|c|c|}
\hline GO terms level 1 & GO terms level 2 & No. of proteins \\
\hline \multirow[t]{13}{*}{ Biological process } & Cellular process & 228 \\
\hline & Metabolic process & 160 \\
\hline & Single-organism process & 153 \\
\hline & Biological regulation & 141 \\
\hline & Cellular component organization or biogenesis & 99 \\
\hline & Response to stimulus & 85 \\
\hline & Localization & 79 \\
\hline & Multicellular organismal process & 55 \\
\hline & Developmental process & 54 \\
\hline & Signaling & 49 \\
\hline & Immune system process & 17 \\
\hline & Multi-organism process & 15 \\
\hline & Other & 31 \\
\hline \multirow[t]{8}{*}{ Cellular component } & Cell & 266 \\
\hline & Organelle & 219 \\
\hline & Membrane & 141 \\
\hline & Macromolecular complex & 108 \\
\hline & Membrane-enclosed lumen & 87 \\
\hline & Extracellular region & 48 \\
\hline & Cell junction & 9 \\
\hline & Other & 10 \\
\hline \multirow[t]{9}{*}{ Molecular function } & Binding & 221 \\
\hline & Catalytic activity & 119 \\
\hline & Molecular function regulator & 25 \\
\hline & Transporter activity & 21 \\
\hline & Structural molecule activity & 14 \\
\hline & Molecular transducer activity & 8 \\
\hline & Signal transducer activity & 7 \\
\hline & Transcription factor activity, protein binding & 7 \\
\hline & Other & 6 \\
\hline
\end{tabular}

epithelial cells, and together with junctional adhesion molecule A [29] are responsible for controlling leukocyte migration into tissues. These results were confirmed by the pathway enrichment results, which showed cell adhesion molecules (CAMs), glycolysis/gluconeogenesis, pentose phosphate pathway and purine metabolism.

We found that $S$. agalactiae may reduce the immune response in mammary tissue by blocking the pathogen recognition pathways and reducing leukocyte migration. Glutathione is an antioxidant tripeptide widely existing in cells, which has many important physiological functions, such as maintaining the stability of intracellular molecules and participating in amino acid transport [30]. Our results showed that the expression of glutathione $S$-transferase P1 (GSTP1), an enzyme that catalyzes the transfer of GSH to intracellular molecules, was downregulated. Furthermore, it has been reported that GSTP1 is involved in glutathione metabolism and could reduce excessive ROS and maintain redox balance [31]. Other studies showed that GSTP1 inhibited cell apoptosis through a mitochondrial and MAPK-associated pathway [32]. In summary, these results may provide a better understanding of the mechanism of the injury caused by $S$. agalactiae and the apoptosis of bMECs, which can be tested by further research.

Among the top ten differentially expressed proteins, dimethylarginine dimethylaminohydrolase1 (DDAH1), peroxidase 6 (PRDX6), and epithelial cell adhesion molecule (EPCAM) deserve particular attention. DDAH1 is an enzyme that metabolizes methylated arginine to citrulline and methylamine. Dai et al. [33] stated that it may be related to tissue differentiation during breast development, and we speculate that it may be related to cell differentiation. Studies have shown that PRDX6 can prevent oxidative damage of mammary glands in mice [34]. The significant down-regulation of PRDX6 in this study 
Table 3 Distribution of down-regulated proteins in GO secondary annotations (T/C)

\begin{tabular}{|c|c|c|}
\hline GO terms level 1 & GO terms level 2 & No. of proteins \\
\hline \multirow[t]{14}{*}{ Biological process } & Cellular process & 463 \\
\hline & Single-organism process & 318 \\
\hline & Biological regulation & 318 \\
\hline & Metabolic process & 314 \\
\hline & Cellular component organization or biogenesis & 191 \\
\hline & Response to stimulus & 152 \\
\hline & Localization & 131 \\
\hline & Multicellular organismal process & 123 \\
\hline & Developmental process & 121 \\
\hline & Signaling & 77 \\
\hline & Multi-organism process & 35 \\
\hline & Immune system process & 34 \\
\hline & Biological adhesion & 27 \\
\hline & Other & 58 \\
\hline \multirow[t]{9}{*}{ Cellular component } & Cell & 588 \\
\hline & Organelle & 521 \\
\hline & Macromolecular complex & 236 \\
\hline & Membrane & 220 \\
\hline & Membrane-enclosed lumen & 198 \\
\hline & Extracellular region & 193 \\
\hline & Cell junction & 65 \\
\hline & Supramolecular complex & 45 \\
\hline & Other & 17 \\
\hline \multirow[t]{9}{*}{ Molecular function } & Binding & 506 \\
\hline & Catalytic activity & 180 \\
\hline & Structural molecule activity & 55 \\
\hline & Molecular function regulator & 46 \\
\hline & Nucleic acid binding transcription factor activity & 17 \\
\hline & Transporter activity & 17 \\
\hline & Transcription factor activity, protein binding & 16 \\
\hline & Signal transducer activity & 10 \\
\hline & Other & 27 \\
\hline
\end{tabular}

may also mean that it is a target of $S$. agalactiae. EpCAM mediates cell-to-cell contact and recruits tight junction proteins to form an epithelial barrier against penetration by pathogenic bacteria and tissue invasion. Damage to the cells of the epithelial layer can lead to bacterial infection and cell death [35]. Hence, the decrease in EPCAM protein may reduce the integrity of bMECs in bovine mammary tissue allowing further tissue invasion by $S$. agalactiae. EPCAM also participates in apoptosis-related pathways, regulating the balance of the apoptotic promoter, Bax, and the anti-apoptotic molecule, Bcl-2. Gao et al. [36] showed that EpCAM could down-regulate the expression of Bcl-2 through an ERK1/2 signaling pathway, promote cell apoptosis, inhibit cell proliferation and cause cell cycle arrest. These effects are contrary to the results of our in vitro experiments and warrant further study. Histone H2B, non-histone chromosomal protein HMG-17 and transcription factor BTF3 are nuclear proteins that play important roles in cells. Further study on these proteins may discover new mechanisms in the process of S. agalactiae infection. 


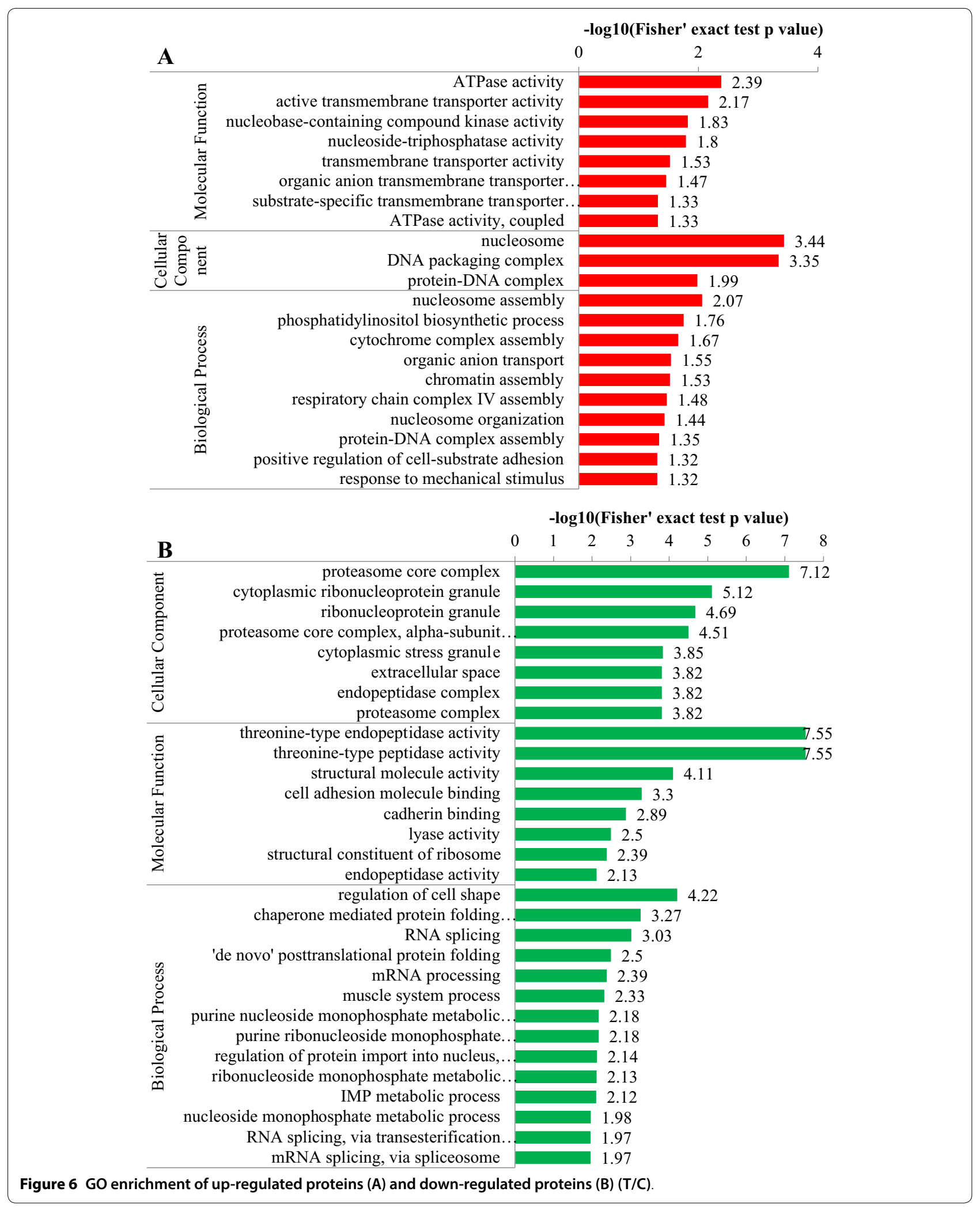




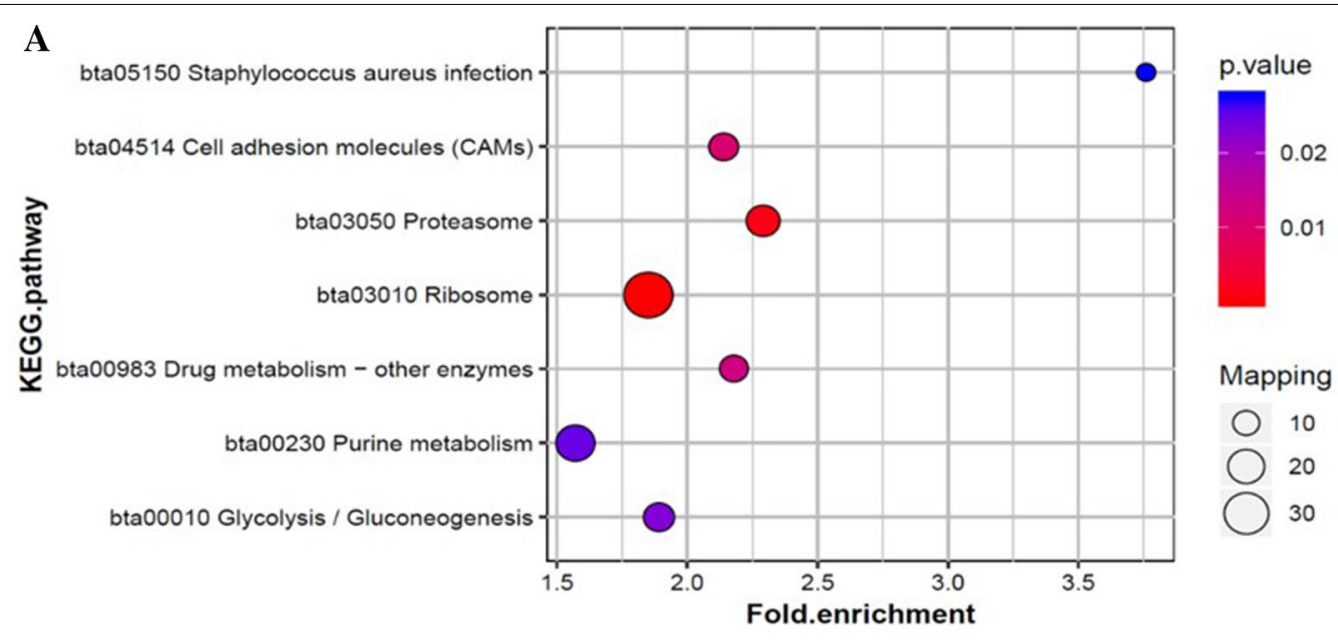

B

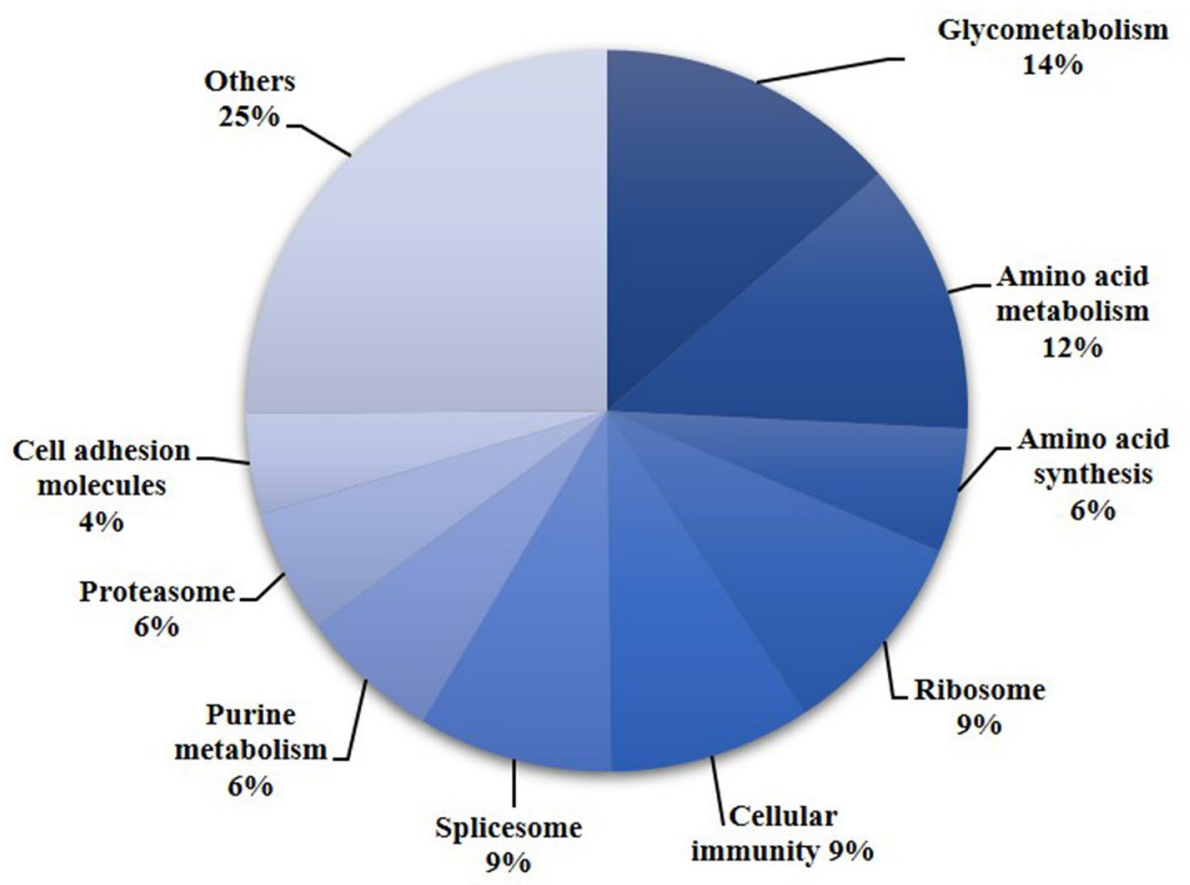

Figure 7 KEGG pathway enrichment

\section{Conclusion}

Altogether, these results showed that incubation of bMECs with $S$. agalactiae induced an acute inflammatory response, promoted apoptosis and caused disruption of cell membranes and organelles. Our data suggest that $S$. agalactiae infection may affect cell proliferation and milk composition by inhibiting ATP synthesis. S. agalactiae may also avoid immune attack by inhibiting the pathogen recognition pathways and reducing the migration of immune cells. These results 
Table 4 Top 10 differentially up-regulated proteins

\begin{tabular}{llll}
\hline Gene name & Protein description & T/C ratio & T/C $\boldsymbol{p}$ value \\
\hline C3orf58 & Uncharacterized protein & 95.822 & 0.0090228 \\
CLYBL & Uncharacterized protein & 66.21 & 0.0173614 \\
CFAP46 & Uncharacterized protein & 34.48 & 0.0038223 \\
MATN4 & Uncharacterized protein & 33.407 & $6.7991 \mathrm{E}-08$ \\
RERE & Uncharacterized protein & 32.414 & 0.00099539 \\
PDE11A & Phosphodiesterase & 30.873 & 0.000019091 \\
SEL1L3 & Uncharacterized protein & 27.238 & $6.0201 \mathrm{E}-08$ \\
KMT5C & Uncharacterized protein & 23.274 & 0.0026386 \\
DHX35 & Uncharacterized protein & 23.18 & $2.3707 \mathrm{E}-06$ \\
SENP6 & Uncharacterized protein & 20.006 & $1.1863 \mathrm{E}-06$ \\
\hline
\end{tabular}

Table 5 Top 10 differentially down-regulated proteins

\begin{tabular}{llll}
\hline Gene name & Protein description & T/C ratio & T/C $\boldsymbol{p}$ value \\
\hline ZFAND2B & Uncharacterized protein & 0.05 & 0.000020886 \\
H2B & Histoneh2B & 0.075 & 0.000020316 \\
TNRC6B & Uncharacterized protein & 0.083 & $3.6866 \mathrm{E}-08$ \\
WIPF2 & Uncharacterized protein & 0.087 & 0.00020302 \\
FAM107B & Protein FAM107B & 0.101 & $8.7112 \mathrm{E}-08$ \\
HMGN2 & Non-histone chromosomal & 0.117 & $1.4851 \mathrm{E}-06$ \\
& $\quad$ proteinhMG-17 & & \\
BTF3 & Transcription factor BTF3 & 0.128 & $2.2885 \mathrm{E}-07$ \\
ENSA & Alpha-endosulfine & 0.129 & $2.0782 \mathrm{E}-07$ \\
DAP & Death-associated protein 1 & 0.133 & 0.000096505 \\
SRRM1 & Uncharacterized protein & 0.135 & $2.7367 \mathrm{E}-07$ \\
\hline
\end{tabular}

need to be further validated, but this study does suggest potential targets for blocking S. agalactiae from invading bovine mammary glands.

\section{Acknowledgements \\ Jinjin Tong thanks the China Postdoctoral Science Foundation and the Beijing Postdoctoral Science Foundation for their financial support. Linshu Jiang also thanks the Millions of Beijing Talent Projects candidates for the financial support.}

\section{Authors' contributions}

$L J, Y Z$ and $B X$ conceived and designed the research. MS, DY and $\mathrm{HZ}$ performed the experiments. MS wrote the manuscript and JT revised it. All authors discussed the results and commented on the manuscript. All authors read and approved the final manuscript.

\section{Funding}

This study was funded by the Project of National Nature Science Foundation of China (Grant No. 31802091, No. 31702302 and No. 31772629), the National Key Research and Development Plan (2016YFD0700205, 2016YFD0700201, 2017YFD0701604) and the Beijing Talents Projects.

\section{Competing interests}

The authors declare that they have no competing interests.

Received: 27 July 2019 Accepted: 19 May 2020

Published online: 03 August 2020

\section{References}

1. Seegers H, Fourichon C, Beaudeau F (2003) Production effects related to mastitis and mastitis economics in dairy cattle herds. Vet Res 34(5):475-491

2. Huang JM, Wang $X G$, Jiang $Q$, Sun $Y$, Yang $C H$, Ju ZH, Hao HS, Wang CF, Zhong JF, Zhu HB (2016) Identification of CD14 transcript in blood polymorphonuclear neutrophil leukocytes and functional variation in Holsteins. Genet Mol Res GMR 15(2):gmr7932

3. Mungube EO, Tenhagen BA, Regassa F, Kyule MN, Shiferaw Y, Kassa T, Baumann MPO (2005) Reduced milk production in udder quarters with subclinical mastitis and associated economic losses in crossbred dairy cows in Ethiopia. Trop Anim Health Prod 37(6):503-512

4. Schukken YH, Günther J, Fitzpatrick J, Fontaine MC, Goetze L, Holst O, Leigh J, Petzl W, Schuberth HJ, Sipka A (2011) Host-response patterns of intramammary infections in dairy cows. Vet Immunol Immunopathol 144(3):270-289

5. Ezzat Alnakip M, Quintelabaluja M, Böhme K, Fernándezno I, Caamañoantelo S, Calomata P, Barrosvelázquez J, Ezzat Alnakip M, Quintelabaluja M, Böhme K (2014) The immunology of mammary gland of dairy ruminants between healthy and inflammatory conditions. J Vet Med 2014:1-31

6. Eckel EF, Ametaj BN (2016) Invited review: role of bacterial endotoxins in the etiopathogenesis of periparturient diseases of transition dairy cows. J Dairy Sci 99(8):S0022030216302764

7. Chen D, Yuan X, Liu L, Zhang M, Qu B, Zhen Z, Gao X (2017) Mitochondrial ATAD3A regulates milk biosynthesis and proliferation of mammary epithelial cells from dairy cow via the mTOR pathway. Cell Biol Int 42(12):533-542

8. Mora A, Komander D, van Aalten DM, Alessi DR (2004) PDK1, the master regulator of AGC kinase signal transduction. Seminars in cell \& developmental biology. Elsevier, New York, pp 161-170

9. Almeida A, Alves-Barroco C, Sauvage E, Bexiga R, Albuquerque P, Tavares F, Santos-Sanches I, Glaser P (2016) Persistence of a dominant bovine lineage of group B Streptococcus reveals genomic signatures of host adaptation. Environ Microbiol 18(11):4216-4229

10. Pang M, Sun L, He T, Bao H, Zhang L, Zhou Y, Zhang H, Wei R, Liu Y, Wang R (2017) Molecular and virulence characterization of highly prevalent Streptococcus agalactiae circulated in bovine dairy herds. Vet Res 48(1):65

11. Beigverdi R, Jabalameli F, Mirsalehian A, Hantoushzadeh S, Boroumandi S, Taherikalani M, Emaneini M (2014) Virulence factors, antimicrobial susceptibility and molecular characterization of Streptococcus agalactiae isolated from pregnant women. Acta Microbiol Immunol Hung 61(4):425

12. Lamkanfi M, Dixit VM (2010) Manipulation of host cell death pathways during microbial infections. Cell Host Microbe 8(1):44-54

13. Bannerman DD (2009) Pathogen-dependent induction of cytokines and other soluble inflammatory mediators during intramammary infection of dairy cows. J Anim Sci 87(13 Suppl):10

14. Trigo G, França A, Dinis M, Rui GDC, Andrade E, Ferreira P, Tavares D (2009) Inflammatory cell infiltration and inflammatory cytokines: indicators of Streptococcus agalactiae infection in experimental mouse mastitis. Vet Immunol Immunopathol 128(1-3):258

15. Wang Z, Guo C, Xu Y, Liu G, Lu C, Liu Y (2014) Two novel functions of hyaluronidase from Streptococcus agalactiae are enhanced intracellular survival and inhibition of proinflammatory cytokine expression. Infect Immun 82(6):2615

16. Zbinden C, Stephan R, Johler S, Borel N, Bünter J, Bruckmaier RM, Wellnitz O (2014) The inflammatory response of primary bovine mammary epithelial cells to Staphylococcus aureus strains is linked to the bacterial phenotype. PLoS One 9(1):e87374

17. Mcmanaman JL, Neville MC (2003) Mammary physiology and milk secretion. Adv Drug Deliv Rev 55(5):629-641

18. Cerwenka H, Aigner R, Bacher H, Werkgartner G, El-Shabrawi A, Quehenberger F, Mischinger H (1999) TUM2-PK (pyruvate kinase type tumor M2), CA19-9 and CEA in patients with benign, malignant and metastasizing pancreatic lesions. Anticancer Res 19(1B):849

19. Janjanam J, Singh S, Jena MK, Varshney N, Kola S, Kumar S, Kaushik JK, Grover S, Dang AK, Mukesh M (2014) Comparative 2D-DIGE proteomic analysis of bovine mammary epithelial cells during lactation reveals protein signatures for lactation persistency and milk yield. PLoS One 9(8):e102515 
20. Kubo H (2011) Cloning and expression analysis of putative glyceraldehyde-3-phosphate dehydrogenase genes in Pilobolus crystallinus. Mycoscience 52(2):99-106

21. Wei XS, Cai CJ, He JJ, Yu C, Mitloehner F, Liu BL, Yao JH, Cao YC (2018) Effects of biotin and nicotinamide supplementation on glucose and lipid metabolism and milk production of transition dairy cows. Anim Feed Sci Technol 237:106-117

22. Gilbert FB, Cunha P, Jensen K, Glass EJ, Foucras G, Robertgranié C, Rupp $R$, Rainard P (2013) Differential response of bovine mammary epithelial cells to Staphylococcus aureus or Escherichia coli agonists of the innate immune system. Vet Res 44(1):1-23

23. Porcherie A, Cunha P, Trotereau A, Roussel P, Gilbert FB, Rainard P, Germon P (2012) Repertoire of Escherichia coli agonists sensed by innate immunity receptors of the bovine udder and mammary epithelial cells. Vet Res 43(1):14

24. Groettrup M, Soza A, Eggers M, Kuehn L, Dick TP, Schild H, Rammensee HG, Koszinowski UH, Kloetzel PM (1996) A role for the proteasome regulator PA28alpha in antigen presentation. Nature 381(6578):166-168

25. Matsunaga Y, Saibara T, Kido H, Katunuma N (1993) Participation of cathepsin B in processing of antigen presentation to MHC class II. FEBS Lett 324(3):325-330

26. Nakken B, Varga T, Szatmari I, Szeles L, Gyongyosi A, Illarionov PA, Dezso B, Gogolak P, Rajnavolgyi E, Nagy L (2011) Peroxisome proliferator-activated receptor $\gamma$-regulated cathepsin $D$ is required for lipid antigen presentation by dendritic cells. J Immunol 187(1):240-247

27. René M, Hang HC, Mintern JD, You-Me K, Armelle C, Mikio N, Kenji Y, Kanae SN, Ikuko HN, Ploegh HL (2005) Asparagine endopeptidase is not essential for class II MHC antigen presentation but is required for processing of cathepsin L in mice. J Immunol 174(11):7066-7074

28. Lin X, Shang X, Manorek G, Howell SB (2013) Regulation of the epithelial-mesenchymal transition by claudin-3 and claudin-4. PLoS One 8(6):e67496

29. Vetrano S, Rescigno M, Cera MR, Correale C, Rumio C, Doni A, Fantini M, Sturm A, Borroni E, Repici A (2008) Unique role of junctional adhesion molecule-a in maintaining mucosal homeostasis in inflammatory bowel disease. Gastroenterology 135(1):173-184

30. Meister A, Anderson ME (1960) Glutathione. Annu Rev Biochem 32(6):711-760

31. Boyer TD (1989) The glutathione S-transferases: an update. Hepatology 9(3):486-496

32. Zhang C, Yuan X, Mao W, Yue L, Kong X, Gao Y, Luo L, Yin Z (2010) Inhibition of cadmium-induced apoptosis by glutathione S-transferase P1 via mitogen-activated protein kinases and mitochondrial pathways. Environ Toxicol Pharmacol 30(2):202-208

33. Dai WT, Wang QJ, Zou YX, White RR, Liu JX, Liu HY (2017) Short communication: comparative proteomic analysis of the lactating and nonlactating bovine mammary gland. J Dairy Sci 100(7):S0022030217303582

34. Wang X, Phelan SA, Forsman-Semb K, Taylor EF, Petros C, Brown A, Lerner $C P$, Paigen B (2003) Mice with targeted mutation of peroxiredoxin 6 develop normally but are susceptible to oxidative stress. J Biol Chem 278(27):25179-25190

35. Lei Z, Maeda T, Tamura A, Nakamura T, Yamazaki Y, Shiratori H, Yashiro K, Tsukita S, Hamada H (2012) EpCAM contributes to formation of functional tight junction in the intestinal epithelium by recruiting claudin proteins. Dev Biol 371(2):136-145

36. Gao J, Yan Q, Liu S, Yang X (2014) Knockdown of EpCAM enhances the chemosensitivity of breast cancer cells to 5 -fluorouracil by downregulating the antiapoptotic factor BCl-2. PLoS One 9(7):e102590

37. Fu Y, Liu B, Feng X, Liu Z, Liang D, Li F, Li D, Cao Y, Feng S, Zhang X (2013) Lipopolysaccharide increases Toll-like receptor 4 and downstream Toll-like receptor signaling molecules expression in bovine endometrial epithelial cells. Vet Immunol Immunopathol 151(1-2):20-27

\section{Publisher's Note}

Springer Nature remains neutral with regard to jurisdictional claims in published maps and institutional affiliations.
Ready to submit your research? Choose BMC and benefit from:

- fast, convenient online submission

- thorough peer review by experienced researchers in your field

- rapid publication on acceptance

- support for research data, including large and complex data types

- gold Open Access which fosters wider collaboration and increased citations

- maximum visibility for your research: over $100 \mathrm{M}$ website views per year

At $\mathrm{BMC}$, research is always in progress.

Learn more biomedcentral.com/submissions 